\title{
Inhibition of Astrocyte Glutamate Uptake by Reactive Oxygen Species: Role of Antioxidant Enzymes
}

\author{
Olivier Sorg, Thomas F. W. Horn, Naichen Yu, \\ Donna L. Gruol, and Floyd E. Bloom \\ Department of Neuropharmacology, The Scripps Research Institute, \\ La Jolla, California, U.S.A.
}

\begin{abstract}
Background: The recent literature suggests that free radicals and reactive oxygen species may account for many pathologies, including those of the nervous system.

Materials and Methods: The influence of various reactive oxygen species on the rate of glutamate uptake by astrocytes was investigated on monolayers of primary cultures of mouse cortical astrocytes.

Results: Hydrogen peroxide and peroxynitrite inhibited glutamate uptake in a concentration-dependent manner. Addition of copper ions and ascorbate increased the potency and the efficacy of the hydrogen peroxide effect, supporting the potential neurotoxicity of the hydroxyl radical. The free radical scavenger dimethylthiourea effectively eliminated the inhibitory potential of a mixture containing hydrogen peroxide, copper sulphate, and ascorbate on the rate of glutamate transport into astro-
\end{abstract}

cytes. The inhibitory effect of hydrogen peroxide on glutamate uptake was not altered by the inhibition of glutathione peroxidase, whereas the inhibition of catalase by sodium azide clearly potentiated this effect. Superoxide and nitric oxide had no effect by themselves on the rate of glutamate uptake by astrocytes. The absence of an effect of nitric oxide is not due to an inability of astrocytes to respond to this substance, since the same cultures did respond to nitric oxide with a sustained increase in cytoplasmic free calcium.

Conclusion: These results confirm that reactive oxygen species have a potential neurotoxicity by means of impairing glutamate transport into astrocytes, and they suggest that preventing the accumulation of hydrogen peroxide in the extracellular space of the brain, especially during conditions that favor hydroxyl radical formation, could be therapeutic.

\section{INTRODUCTION}

During the last decade, an increasing number of pathologies have been attributed at least in part to the actions of reactive oxygen species (ROS). These unstable and highly reactive intermediates originate from the reaction of the dioxygen molecule in its triplet state $\left({ }^{3} \mathrm{O}_{2}\right)$ with elements of

Dr. Olivier Sorg's present address is Institut de Physiologie, Faculté de Médecine, CH-1005 Lausanne, Switzerland. Address correspondence and reprint requests to: Dr. Floyd E. Bloom, Department of Neuropharmacology, The Scripps Research Institute, 10550 North Torrey Pines Rd., Mail Code SBR-1, La Jolla, CA 92037, U.S.A. Tel: 619-784-9730; Fax: 619-784-8851; e-mail: fbloom@scripps.edu biological tissues. The first molecule to be formed in the reduction of triplet dioxygen is always the superoxide radical $\left(\mathrm{O}_{2}^{-}\right)$. This relatively unstable intermediate can dismutate spontaneously to form hydrogen peroxide $\left(\mathrm{H}_{2} \mathrm{O}_{2}\right)$, and the reaction between these species can lead to the formation of hydroxyl radical $(\cdot \mathrm{OH})$, the molecule possessing the highest oxidant potential that can be found in biological tissues (1). Superoxide dismutase, associated with catalase or glutathione peroxidase (GPX), provides the most efficient endogenous means to scavenge superoxide and hydrogen or organic peroxides before they have time to react and produce hydroxyl radicals 
$(1,2)$. Recently, various groups (such as Volterra et al. [3] and Piani et al. [4]) have shown that hydrogen peroxide-generating systems interact with the active transport of glutamate (Glu) into astrocytes, resulting in a significant inhibition of Glu uptake and leading to yet another means to produce neurotoxicity. Glu is considered to be the most prevalent excitatory neurotransmitter in the brain (5). Extracellular Glu is normally kept at low concentrations by the ability of astrocytes to accumulate this amino acid efficiently (6). However, high concentrations of Glu in the extracellular space can be neurotoxic (7-9).

In this study, our purpose was (1) to compare the ability of specific oxygen-derived intermediates to interfere with the Glu transport of primary mouse astrocyte cultures, and (2) to evaluate the importance of the possible protective mechanisms provided by catalase and glutathione peroxidase.

\section{MATERIALS AND METHODS}

\section{Cell Culture}

Primary cultures of cerebral cortical astrocytes were prepared from C57BL/6JxSJL new-born mice (1-2 days old) as previously described (10). Briefly, forebrains were removed aseptically from the skulls, the meninges were excised carefully under a dissecting microscope, and the neocortex was dissected. The cells were dissociated by passage through needles of decreasing gauges (16Gl, 19Gl, 25Gl) two to three times with a 10-ml syringe. Trypsin was not used for tissue dissociation. The cells were seeded at a density of $10^{5}$ cells per $\mathrm{cm}^{2}$ on 6-well plates in Dulbecco's modified Eagle's medium (DMEM) containing $10 \%$ fetal calf serum (FCS) and $25 \mathrm{mM}$ glucose in a final volume of $2 \mathrm{ml}$ per well and incubated at $37^{\circ} \mathrm{C}$ in an atmosphere containing $5 \% \mathrm{CO}_{2}$ at $95 \%$ humidity. The culture medium was renewed 3-4 days after seeding and subsequently twice per week. These conditions yield astrocyte cultures containing over $90 \%$ glial fibrillary acidic protein (GFAP) immunoreactive cells (11).

\section{${ }^{3}$ H-Glu Uptake Assay}

Experiments on ${ }^{3} \mathrm{H}$-Glu uptake were performed on primary cultures of cerebral cortical astrocytes at about 14 days in vitro (DIV) after they reached confluence. Reagents were added for a defined period of time prior to ${ }^{3} \mathrm{H}$-Glu uptake (see cor- responding figure legends). The medium was replaced by $1 \mathrm{ml}$ fresh medium containing $50 \mu \mathrm{M}$ Glu and $18.5 \mathrm{kBq}(9.25 \mathrm{pmol})$ of ${ }^{3} \mathrm{H}$-Glu. The uptake assay was terminated 15 min later by aspiration of the assay medium and washing the cells three times with $4 \mathrm{ml}$ ice-cold phosphatebuffered saline (PBS) containing $5 \mathrm{mM}$ Glu. Astrocytes were then lysed by $2 \mathrm{ml}$ of $10 \mathrm{mM} \mathrm{NaOH}$ containing $0.1 \%$ Triton X-100 and a $500-\mu \mathrm{l}$ aliquot was assayed for ${ }^{3} \mathrm{H}$ by liquid scintillation counting. The protein content was measured by the method of Bradford (12) in $100 \mu \mathrm{l}$ of the remaining lysate. Results are expressed as the mean \pm SEM of three separate experiments. For Figs. 1, 3, and 4, ANOVA analyses were performed, using Bonferroni (Figs. 1-4) or Dunnett (Tables 1,2 , and 4) post-tests; ${ }^{*} p<0.05,{ }^{* *} p<$ $0.01,{ }^{* * *} p<0.001$.

\section{Nitric Oxide Monitoring}

Control medium was stored in $40 \mathrm{ml}$ HPLCscrew cap vials sealed by a Teflon septum (National Scientific Company, Lawrenceville, GA). To prevent nitric oxide (NO) oxidation, deoxygenated medium was performed by extensive bubbling with nitrogen for $15 \mathrm{~min}$ (Air Liquide, San Diego) through a long cannulae penetrating the septum. NO containing medium (NO-medium) was prepared by passing a gas stream of $5 \%$ $\mathrm{NO}$ in $95 \% \mathrm{~N}_{2}$ (Air Liquide) through the medium for at least $15 \mathrm{~min}$. NO-medium was always prepared fresh immediately before use and diluted 1:10 with deoxygenated control medium. To ensure identical NO concentration during different experiments, the NO concentration was monitored continuously with an ISO-NO meter (World Precision Instruments [WPI], Sarasota, FL) connected to a computerized on-line data acquisition system (Duo 18, WPI, Sarasota, FL). The electrode was inserted into a $\mathrm{T}$-adapter which was placed in the medium flow between the peristaltic pump and tissue chamber.

\section{Calcium Imaging}

Calcium concentrations in astrocytes were estimated using the Fura-2 method as described earlier $(13,14)$. In brief, calcium imaging experiments were performed on astrocytes in confluent monolayers cultured on glass coverslips at 14 DIV. Cell cultures were incubated in $3 \mu \mathrm{M}$ Fura-2 AM (Molecular Probes, Eugene, OR) for $45 \mathrm{~min}$ at $37^{\circ} \mathrm{C}$ in physiological saline (composition in $\mathrm{mM}$ : $\mathrm{NaCl}, 140 ; \mathrm{KCl}, 3.5 ; \mathrm{KH}_{2} \mathrm{PO}_{4}, 0.4$; 

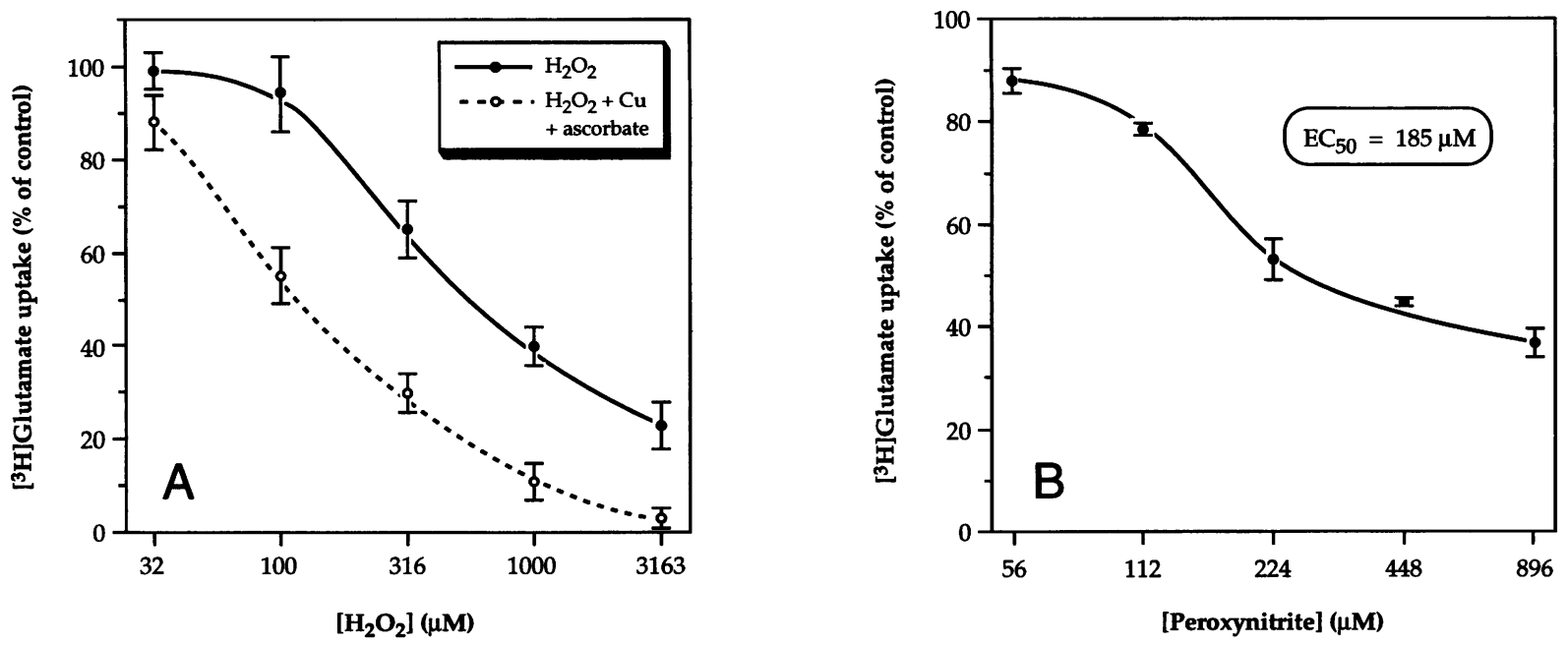

FIG. 1. Concentration-dependent inhibition by hydrogen peroxide and peroxynitrite of Glu uptake: potentiation by copper ions and ascorbate

(A) $\mathrm{H}_{2} \mathrm{O}_{2}, \mathrm{CuSO}_{4}(25 \mu \mathrm{M})$, and ascorbate $(100 \mu \mathrm{M})$ were added $10 \mathrm{~min}$ before incubation with ${ }^{3} \mathrm{H}$-Glu. (B) Peroxynitrite was added immediately after addition of the ${ }^{3} \mathrm{H}$-Glu solution. The symbols - and $\mathrm{O}$ indicate the uptake levels for the curves of $\mathrm{H}_{2} \mathrm{O}_{2}$ alone and $\mathrm{H}_{2} \mathrm{O}_{2}+\mathrm{CuSO}_{4}+$ ascorbate, respectively (A).

$\mathrm{Na}_{2} \mathrm{HPO}_{4}, 1.25 ; \mathrm{CaCl}_{2}, 2.2 ; \mathrm{MgSO}_{2}, 2$; glucose, 10; HEPES-NaOH, 10 at $\mathrm{pH} 7.3$ ) and washed for 30 min before mounting onto a perfusion chamber stage of an inverted Nikon Microscope equipped with epifluorescence, a silicon-intensified target (SIT) camera (Dage) and an LEP filter wheel (LUDL Electronic Products) fitted with appropriate fluorescence filters (Omega Optical). Real-time digitized display, image acquisition, and $\mathrm{Ca}^{2+}$ measurements were made with MCID imaging software (Imaging Research, Inc.). Dye loading and all experiments were performed at room temperature $\left(23^{\circ} \mathrm{C}\right)$. Calibration of the system was performed as described in detail earlier $(15,16)$.

Physiological saline in sealed Erlenmeyer beakers was deoxygenated by extensive bubbling with nitrogen $(20 \mathrm{~min})$. NO-stock solution was prepared by bubbling physiological saline with pure NO in sealed containers. Dilutions were made by transfer of NO-stock physiological saline to deoxygenated physiological saline. The diluted NOsolution was superfused onto the cell cultures. NO concentrations in the bath were monitored by a NO sensitive electrode (ISO-NO meter, WPI).

$\left[\mathrm{Ca}^{2+}\right]_{\mathrm{i}}$ was monitored while astrocytes were superfused with physiological saline for $8 \mathrm{~min}$ followed by a 20 min-period of superfusion with NO-containing physiological saline, which was replaced by physiological saline during a subsequent period of $30 \mathrm{~min}$. During the NO-application, the concentration of NO in the superfusion chamber increased up to $10 \mu \mathrm{M}$. One other sub- set of cell cultures (controls) was superfused with NO-containing physiological saline that had been bubbled with oxygen to metabolize the NO and subsequently deoxygenated by bubbling with $\mathrm{N}_{2}$.

\section{Reagents}

Superoxide was produced either by mixing $1 \mathrm{mM}$ xanthine with $200 \mathrm{mU} / \mathrm{ml}$ xanthine oxidase $5 \mathrm{~min}$ prior to addition to the cultures, or by direct application of its potassium salt (Sigma), as mentioned in the figure and table legends. The former yields $6.5 \mu \mathrm{mol}$ superoxide per liter and per minute, as assayed by the reduction of nitroblue tetrazolium salt by superoxide (not shown) (17). L- $\left[\mathrm{G}-{ }^{3} \mathrm{H}\right]$ glutamic acid $\left({ }^{3} \mathrm{H}-\mathrm{Glu}\right)$ was purchased from Amersham (Little Chalfont, U.K.), N, $\mathrm{N}^{\prime}$-dimethylthiourea (DMTU) from Janssen Chimica USA (Los Angeles, CA), peroxynitrite from Alexis Corporation (San Diego, CA), and the other reagents from Sigma Chemical (St. Louis, MO). The concentration of the stock solution of $\mathrm{H}_{2} \mathrm{O}_{2}$ was determined spectrophotometrically using a value for $\varepsilon_{240}$ of $44\left[\mathrm{M}^{-1} \mathrm{~cm}^{-1}\right]$ (18).

\section{RESULTS}

The uptake of ${ }^{3} \mathrm{H}$-Glu in untreated cultures is time-dependent and is maximal between 10 and 15 min (not shown); thus the incubation time for all uptake experiments was chosen to be $15 \mathrm{~min}$. 


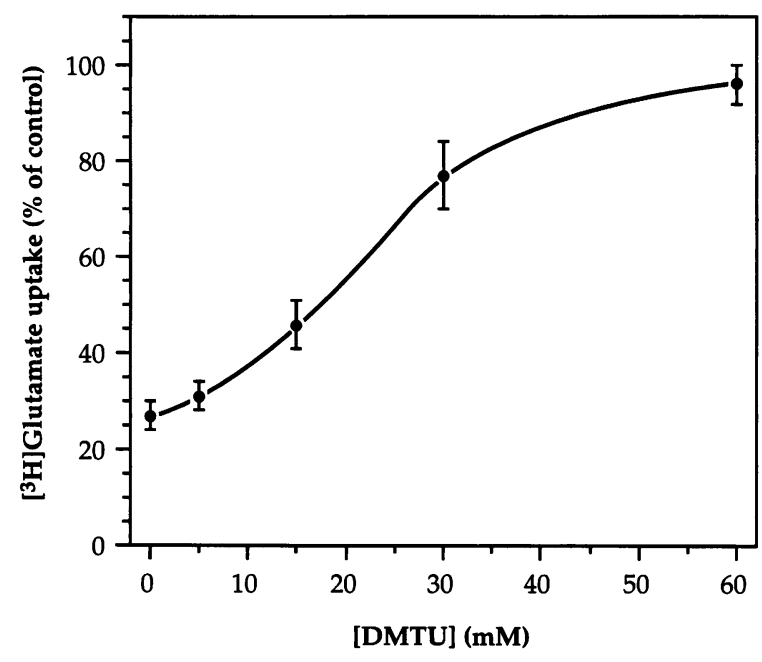

FIG. 2. Hydrogen peroxide-induced inhibition of Glu uptake: protection by DMTU

Various concentrations of DMTU were added in the presence of $0.5 \mathrm{mM} \mathrm{H}_{2} \mathrm{O}_{2}+25 \mu \mathrm{M} \mathrm{CuSO}_{4}+100$ $\mu \mathrm{M}$ ascorbate. DMTU was added $20 \mathrm{~min}$ before incubation with ${ }^{3} \mathrm{H}$-Glu.

In 36 separate assays (used as controls for the experiments), the rate of total Glu uptake into astrocytes has been averaged to $4.48 \pm 0.26$ (nmol/mg protein/min).

\section{Effect of Hydrogen Peroxide and Peroxynitrite on Glu Uptake}

Hydrogen peroxide inhibited Glu uptake into primary astrocyte cultures in a concentrationdependent manner (Fig. 1A). This inhibitory effect was clearly potentiated by the addition of $25 \mu \mathrm{M} \mathrm{CuSO}$ and $100 \mu \mathrm{M}$ ascorbate to the incubation medium. For example, hydrogen peroxide at $3.16 \mathrm{mM}$ decreased the rate of Glu uptake to $23 \%$ of that of untreated cells and the uptake of Glu was almost completely inhibited by the addition of copper and ascorbate to the incubation medium (Fig. 1 A). An examination of astrocytes under the light microscope showed a granulation, indicating a stress condition in the presence of $3.16 \mathrm{mM}$ of hydrogen peroxide.

We then determined if the potent and labile oxidant peroxynitrite, which is known for its ability to promote irreversible oxidations of thiol groups $(19,20)$, was effective in inhibiting Glu uptake into astrocytes. As shown in Fig. 1B, peroxynitrite induced a concentration-dependent inhibition of Glu uptake, with an estimated $\mathrm{EC}_{50}$ of $185 \mu \mathrm{M}$.
TABLE 1. Absence of effect of superoxide on glutamate uptake

\begin{tabular}{lc}
\hline Condition & $\begin{array}{c}\text { Glutamate Uptake } \\
\text { (\% of Control) }\end{array}$ \\
\hline $\mathrm{H}_{2} \mathrm{O}_{2}$ & $46 \pm 2^{\star *}$ \\
$\mathrm{H}_{2} \mathrm{O}_{2}+$ catalase & $100 \pm 3$ \\
Xanthine + xanthine & $48 \pm 1^{\star *}$ \\
oxidase & $101 \pm 3$ \\
$\begin{array}{c}\text { Xanthine + xanthine } \\
\text { oxidase + catalase } \\
\text { Xanthine + xanthine } \\
\text { oxidase + SOD } \\
\text { Potassium superoxide }\end{array}$ & $46 \pm 1^{\star *}$ \\
\hline
\end{tabular}

Reagents were applied at the following concentrations: $\mathrm{H}_{2} \mathrm{O}_{2}, 2 \mathrm{mM}$; xanthine, $1 \mathrm{mM}$; xanthine oxidase, $200 \mathrm{mU} /$ $\mathrm{ml}$; catalase, $800 \mathrm{U} / \mathrm{ml}$; SOD, $100 \mathrm{U} / \mathrm{ml}$; potassium superoxide, $1 \mathrm{mM} . \mathrm{H}_{2} \mathrm{O}_{2}$, the mixture containing xanthine and xanthine oxidase, and potassium superoxide were added 10 min before incubation with ${ }^{3} \mathrm{H}$ glutamate.

$\star * p<0.01$

\section{Protection by DMTU}

DMTU, a sulphydryl antioxidant able to react with either hydrogen peroxide or hydroxyl radicals (21), prevented the reactive oxygen species-induced inhibition of Glu uptake in a concentration-dependent manner. In the presence of $0.5 \mathrm{mM}$ hydrogen peroxide, $25 \mu \mathrm{M} \mathrm{CuSO}_{4}$, and $100 \mu \mathrm{M}$ ascorbate, the rate of Glu uptake was $27 \%$ that of untreated cells, but a 20 -min pretreatment with $60 \mathrm{mM}$ DMTU restored the rate of Glu transport to $96 \%$ that of untreated cells (Fig. 2).

\section{Effect of Superoxide}

We next examined the superoxide radical anion, another well-known reactive oxygen species, to evaluate its effect on glutamate uptake. Addition of $1 \mathrm{mM}$ potassium superoxide had no effect on the rate of Glu uptake, while a mixture containing $1 \mathrm{mM}$ xanthine plus $200 \mathrm{mU} / \mathrm{ml}$ xanthine oxidase (a superoxide- and hydrogen peroxidegenerating system [22]) inhibited Glu uptake by $52 \%$, a level of inhibition similar to that induced by $2 \mathrm{mM}$ hydrogen peroxide $(54 \%)$ (Table 1 ).

\section{Involvement of Antioxidant Enzymes}

Catalase, a specific hydrogen peroxide scavenger, completely prevented the inhibition of Glu uptake by either hydrogen peroxide or the xanthine 


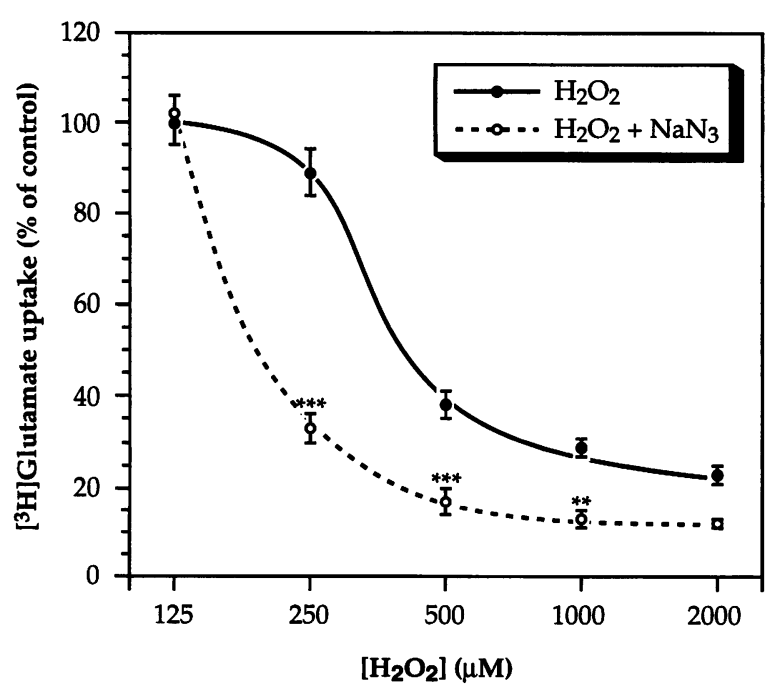

FIG. 3. Hydrogen peroxide-induced inhibition of Glu uptake: potentiation by sodium azide

$\mathrm{NaN}_{3}(5 \mathrm{mM})$ was added $20 \mathrm{~min}$ before incubation with ${ }^{3} \mathrm{H}-\mathrm{Glu}$. The symbols and $\mathrm{O}$ indicate the uptake levels for the curves of $\mathrm{H}_{2} \mathrm{O}_{2}$ alone and $\mathrm{H}_{2} \mathrm{O}_{2}+$ $\mathrm{NaN}_{3}$, respectively.

and xanthine oxidase mixture, whereas the specific superoxide scavenger superoxide dismutase was without effect (Table 1). These observations indicate that superoxide by itself does not affect the uptake of Glu by astrocytes. We used sodium azide, a nonspecific catalase inhibitor (23), which was not cytotoxic in our cultures for the period of time required for Glu uptake assay, as demonstrated by the absence of significant change in extracellular lactate dehydrogenase activity following $35 \mathrm{~min}$ in the presence of $5 \mathrm{mM} \mathrm{NaN}_{3}$ (not shown). Sodium azide proved to be effective as a catalase inhibitor in our system (not shown) and displaced to the left the curve of hydrogen peroxide-induced inhibition of Glu uptake (Fig. 3).

Glutathione peroxidase (GPX) represents a well known endogenous hydrogen peroxide scavenger, which also catalyses the reduction of organic hydroperoxides (24). We used two different means to decrease GPX activity in astrocyte cultures. First, we pre-incubated the cells with L-buthionine-[S,R]-sulfoximine (BSO) or diethylmaleate (DEM), two reagents that have been shown $(25,26)$ to induce a dramatic fall in astrocyte cytoplasmic glutathione, the cosubstrate (or cofactor) of GPX. As shown in Fig. 4, the addition of DEM did not influence the effect of hydrogen peroxide on Glu uptake, while BSO showed only a slight (but insignificant) tendency to reduce the effect of hydrogen peroxide. We

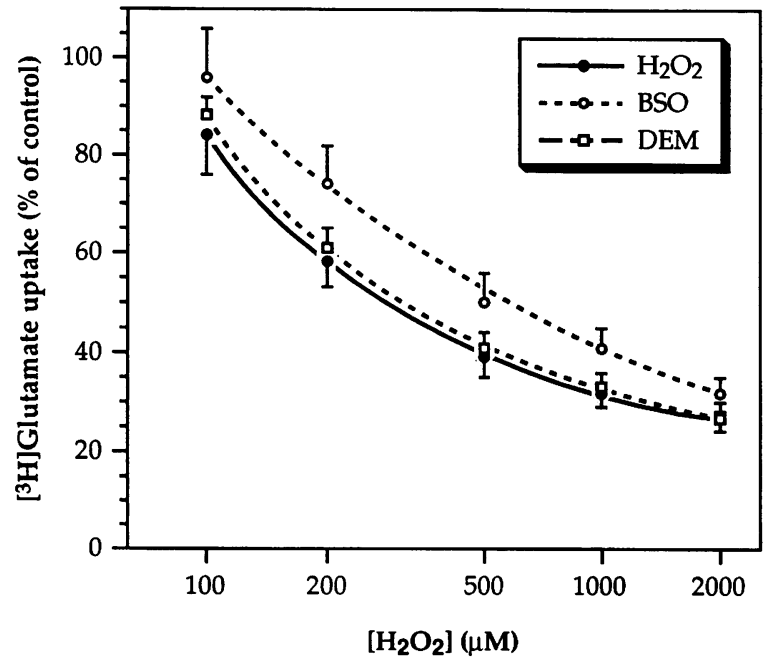

FIG. 4. Hydrogen peroxide-induced inhibition of Glu uptake: effect of reagents inducing a decrease in cellular glutathione

Various concentrations of hydrogen peroxide were added either alone (O) or in the presence of $500 \mu \mathrm{M}$ BSO (O) or $100 \mu \mathrm{M}$ DEM ( $\square$ ). BSO and DEM were added $18 \mathrm{hr}$ before incubation with ${ }^{3} \mathrm{H}$-Glu.

then used two substances that directly inhibit the GPX activity, $N$-ethylmaleimide (NEM) and mercaptosuccinic acid (MSA). NEM potentiated hydrogen peroxide-induced inhibition of Glu uptake and also had a significant effect on Glu uptake by itself (Table 2). On the other hand, when MSA was applied at concentrations up to 1 $\mathrm{mM}$ and pre-incubated for $1 \mathrm{hr}$, it had no significant effect on either basal or hydrogen peroxide-induced levels of Glu uptake (Table 2).

\section{Nitric Oxide}

Another ubiquitous oxygen-derived reactive substance is the presumptive intercellular messenger, nitric oxide (NO). NO is not stable in aqueous solutions in the presence of oxygen $(27,28)$. Thus, we used either NO donors or a NO-gassed aqueous solution previously deoxygenated with $\mathrm{N}_{2}$ to remove dissolved $\mathrm{O}_{2}$ molecules. The actual NO concentrations measured under each condition are shown in Table 3. Neither the NO donors sodium nitroprusside (SNP) or S-nitroso- $N$-acetylpenicillamine (SNAP) (up to $1 \mathrm{mM}$ ) nor NO-containing aqueous solution ( $5 \mu \mathrm{M}$ of free $\mathrm{NO}$ ) significantly changed the level of basal Glu uptake (Table 4).

The lack of effect of NO on Glu uptake could indicate that our astrocytes were simply insensi- 
TABLE 2. Hydrogen peroxide-induced inhibition of glutamate uptake: effect of glutathione peroxidase inhibitors

\begin{tabular}{lllc}
\hline $\begin{array}{l}\mathbf{H}_{2} \mathbf{O}_{2} \\
(\mathbf{m M})\end{array}$ & $\begin{array}{c}\text { MSA } \\
(\mathbf{M M})\end{array}$ & $\begin{array}{c}\text { NEM } \\
(\mathbf{m M})\end{array}$ & $\begin{array}{c}\text { Glutamate Uptake } \\
\text { (\% of Basal) }\end{array}$ \\
\hline 0 & 0 & 0 & $100 \pm 2$ \\
0.5 & 0 & 0 & $34 \pm 3^{* *}$ \\
0.5 & 0.1 & 0 & $36 \pm 2^{\star * a}$ \\
0 & 1 & 0 & $108 \pm 5$ \\
0.5 & 1 & 0 & $35 \pm 1^{* * a}$ \\
0 & 0 & 0.25 & $65 \pm 5^{* *}$ \\
0.5 & 0 & 0.25 & $17 \pm 1^{* * b}$ \\
\hline
\end{tabular}

MSA was added $4 \mathrm{hr}, \mathrm{H}_{2} \mathrm{O}_{2}$ and NEM 10 min before incubation with ${ }^{3} \mathrm{H}$-glutamate.

${ }^{a}$ Not significantly different from $\mathrm{H}_{2} \mathrm{O}_{2}$ alone $(p>0.05)$.

${ }^{b}$ Significantly different from $\mathrm{H}_{2} \mathrm{O}_{2}$ alone $(p<0.01)$.

${ }^{\star *} p<0.01$.

TABLE 3. Concentration of free NO in solution in various conditions producing NO

\begin{tabular}{lc}
\hline NO Source & $\begin{array}{c}\text { Effective NO } \\
\text { Concentration } \\
(\boldsymbol{\mu} \mathbf{M})\end{array}$ \\
\hline SNP 0.1 mM & 0.09 \\
SNP 1 mM & 0.66 \\
SNAP 0.25 mM & 107.00 \\
SNAP 1 mM & 428.00 \\
NO-gased solution dilution 1:10 & 5.00 \\
\hline
\end{tabular}

tive to NO. However, our cultured astrocytes were able to show (Fig. 5) that the NO-containing solution, but not the NO-metabolite containing solution, led to a significant and sustained increase in $\left[\mathrm{Ca}^{2+}\right]_{\mathrm{i}}$, demonstrating that these astrocyte cultures are able to respond to NO, but not in terms of Glu accumulation.

\section{DISCUSSION}

Since the discovery of the enzyme superoxide dismutase in 1969 by McCord and Fridovich (29), superoxide, hydrogen peroxide, and oxygen-derived free radicals, now all included under the term
TABLE 4. Effect of NO and NO donors on glutamate uptake

\begin{tabular}{lr}
\hline $\begin{array}{l}\text { Reagent } \\
\text { (\% of Control) }\end{array}$ & $\begin{array}{r}\text { Glutamate } \\
\text { Uptake }\end{array}$ \\
\hline $\mathrm{H}_{2} \mathrm{O}_{2} 0.2 \mathrm{mM}$ & $66 \pm 5^{* *}$ \\
$\mathrm{H}_{2} \mathrm{O}_{2} 2 \mathrm{mM}$ & $39 \pm 1^{* *}$ \\
$\mathrm{NO}$ & $91 \pm 5$ \\
SNP 0.1 mM & $103 \pm 6$ \\
SNP 1 mM & $96 \pm 5$ \\
SNAP 0.25 mM & $98 \pm 3$ \\
SNAP 1 mM & $100 \pm 3$ \\
\hline
\end{tabular}

All reagents were added immediately before addition of ${ }^{3} \mathrm{H}$-glutamate.

$\star * p<0.01$.

reactive oxygen species (ROS), have been incriminated regularly in multiple pathological processes (1,30-32), including carcinogenesis (33-35), ischemia and reperfusion injury (36-38), and neurodegenerative disorders (39-41). Volterra et al. (3) and Piani et al. (4) recently demonstrated that hydrogen peroxide could inhibit Glu uptake by primary astrocyte cultures. Our results are consistent with this observation.

In this study, we first demonstrated the concentration-dependence of the hydrogen peroxide effect on the inhibition of Glu uptake by astrocytes. It was not possible to establish an $\mathrm{EC}_{50}$ value for this effect of hydrogen peroxide, as the maximally effective concentration would likely have been cytotoxic. The granulation of astrocytes, suggesting stress to the cells, was observed within $25 \mathrm{~min}$ in the presence of $3.16 \mathrm{mM}$ of hydrogen peroxide, even though this concentration was unable to block Glu uptake completely (data not shown). However, as an index of hydrogen peroxide potency, a concentration of $630 \mu \mathrm{M}$ results in a $50 \%$ decrease in basal Glu uptake level (Fig. 1A). The more than 10-fold potentiation of this hydrogen peroxide effect by addition of copper ions and ascorbate strongly argues for an involvement of hydroxyl radicals (Fig. 1A). This highly reactive substance could be produced by a Fenton-type reaction involving a regeneration of $\mathrm{Cu}^{+}$ions by ascorbate (42). The high concentration of DMTU $(60 \mathrm{mM})$ required to provide a good protection of Glu detoxification by astrocytes also accounts for the high reactivity of the deleterious substance(s) scavenged by this nontoxic sulphydryl compound (Fig. 2). 


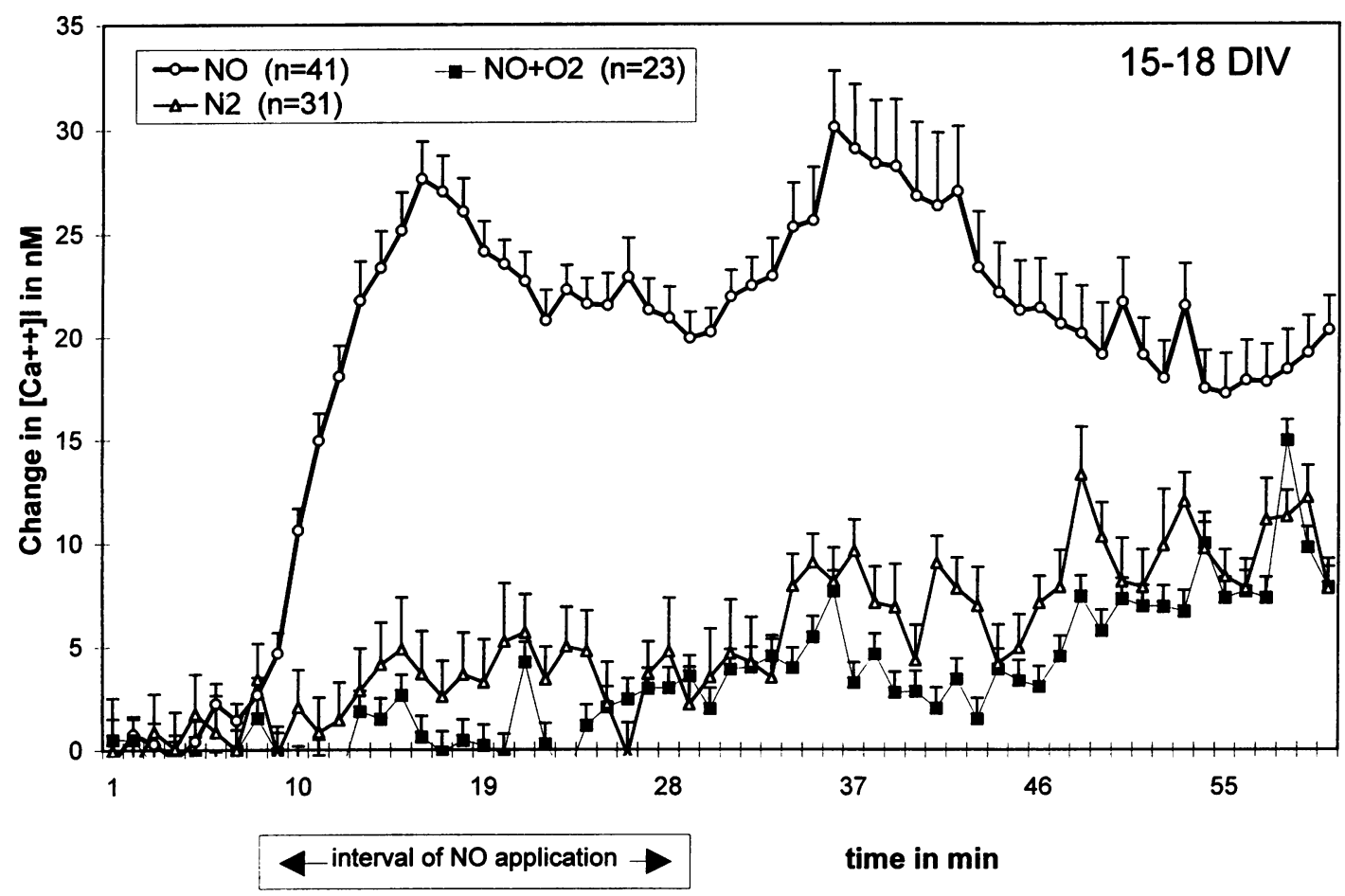

FIG. 5. NO-induced increase in cytoplasmic $\mathrm{Ca}^{2+}$

NO was applied $8 \mathrm{~min}$ after the beginning of $\left[\mathrm{Ca}^{2+}\right]_{\mathrm{i}}$ recording, for a 20 -min period of time. $\left[\mathrm{Ca}^{2+}\right]_{\mathrm{i}}$ was recorded up to $30 \mathrm{~min}$ after NO removal. The graph shows the change in $\left[\mathrm{Ca}^{2+}\right]_{i}$ compared with the basal level, in function of time.

We also showed that superoxide, the intermediate of all reactions involving dioxygen reduction (43), has no effect by itself on Glu uptake, as demonstrated by the absence of superoxide effect of the generating system consisting of xanthine, xanthine oxidase, and catalase, or by direct application of potassium superoxide (Table 1). Furthermore, the lack of effect of NO, another oxygen-derived molecule, cannot be explained by the absence of responsiveness of our astrocyte model to this second messenger, as our cultures did respond to aqueous NO solution with a sustained increase in intracellular calcium (Table 3, Fig. 5). As mentioned above, superoxide and NO by themselves have no effect on Glu uptake into astrocytes, but peroxynitrite, a potent oxidant produced by the addition of NO to superoxide $(20,44-46)$, promoted a concentration-dependent inhibition of Glu uptake, with an estimated $\mathrm{EC}_{50}$ of $185 \mu \mathrm{M}$ (Fig. 1B). Because of its instability at physiological $\mathrm{pH}$ (7.35), peroxynitrite was not preincubated for $10 \mathrm{~min}$ but added immediately following the addition of ${ }^{3} \mathrm{H}$ Glu solution. This could explain a lower maximal effect than that of hydrogen peroxide. These re- sults are consistent with those of Trotti et al. (47), who reported a concentration-dependent inhibition by peroxynitrite of Glu uptake by purified or recombinant glutamate transporters in liposomes. This inhibition seemed to be due to a direct interaction of peroxynitrite with the transporters (47).

Among the two well-known endogenous ROS scavengers, catalase and glutathione peroxidase, only catalase seems to be able to reduce the potential neurotoxicity of hydrogen peroxide (Fig. 3). Sodium azide, a nonspecific catalase inhibitor, potentiated the inhibition of Glu uptake by $\mathrm{H}_{2} \mathrm{O}_{2}$. Sodium azide is also known to inhibit oxydative phosphorylation, resulting in a energy deficit affecting $\mathrm{Na}^{+}-\mathrm{K}^{+}$ATPase, which in turn inhibits the glutamate transporter system. Therefore, the observed effect of sodium azide on Glu uptake may also be attributed in part to altered energy metabolism. Conditions leading either to (1) a decrease in cytoplasmic glutathione, the cosubstrate of GPX (Fig. 4), or (2) a selective inhibition of GPX (Table 2) were unable to potentiate the inhibition of Glu uptake by hydrogen peroxide. NEM, tested as a nonselective GPX 
inhibitor, is a well-known alkylating agent that reacts with nucleophilic groups (48) and could also be expected to alkylate free sulphydryl groups participating in Glu transport, as suggested by Volterra et al. (3). Therefore, the high potency of NEM on hydrogen peroxide-mediated inhibition of Glu uptake could be independent of the inhibition of GPX but related only to the involvement of reduced cysteine amino acids linked to the Glu transporters. On the other hand, mercaptosuccinate (MSA) has been shown to be highly specific for selenolate groups such as the selenocysteine present at the active site of GPX subunits (49). Thus, the lack of effect of MSA on the inhibition of Glu uptake suggests that GPX does not directly participate in the elimination of ROS involved in the Glu-mediated neurotoxicity. The lack of effect of GPX inhibition on $\mathrm{H}_{2} \mathrm{O}_{2}$-induced decrease in Glu uptake could be explained by recent findings that rather than regenerating the GPX/GSH/GS reductase system, NADPH may play a role in maintaining the intergrity and functionality of the catalase, although NADPH is not directly involved in the catalase activity (50). This is consistent with our results that catalase is able to prevent excitotoxicity by scavenging efficiently the excess of the hydrogen peroxide formed in the brain.

One of the enzymes activated by calcium is phospholipase $\mathrm{A}_{2}$, which catalyses the release of arachidonate by phospholipid membranes. This polyunsaturated fatty acid in turn is able to inhibit Glu uptake by astrocytes (50-52). Furthermore, calpains, which transform xanthine dehydrogenase into xanthine oxidase, thus leading to ROS production-especially in the case of an ischemia $(53,54)$-are also activated by calcium. Finally, the hypothesized accumulation of extracellular Glu might not be the only phenomenon occurring during events like ischemia or carcinogenesis. There could also be an increased neurotransmitter release $(55)$ or a hypersensitivity of NMDA receptors. In light of these possibilities, the diminished uptake capacity of astrocytes would still potentiate the pathological Glu levels even more (e.g., a 50\% uptake inhibition of a 10 -fold increased basal Glu release would result in a 20 -fold increased extracellular Glu level). These results confirm the involvement of ROS in excitotoxicity by allowing Glu to accumulate in the extracellular space, leading to a continuous depolarization of neurons, followed by high and sustained calcium influxes $(56,57)$.

\section{ACKNOWLEDGMENTS}

This work was supported in part by MH47680 (F.E.B., N.Y., D.L.G.), Deutscher Akademischer Austauschdienst (T.F.W.H.), and Swiss National Fund (O.S.).

\section{REFERENCES}

1. Halliwell B, Gutteridge JMC. (1989) Free Radicals in Biology and Medicine. Oxford University Press, Oxford.

2. Przedborski S, Donaldson D, Jakowec M, et al. (1996) Brain superoxide dismutase, catalase, and glutathione peroxidase activities in amyotrophic lateral sclerosis. Ann. Neurol. 39: 158-165.

3. Volterra A, Trotti D, Tromba C, Floridi S, Racagni G. (1994) Glutamate uptake inhibition by oxygen free radicals in rat cortical astrocytes. J. Neurosci. 14: 2924-2932.

4. Piani D, Frei K, Pfister HW, Fontana A. (1993) Glutamate uptake by astrocytes is inhibited by reactive oxygen intermediates but not by other macrophage-derived molecules including cytokines, leukotrienes or plateletactivating factor. J. Neuroimmunol. 48: 99104.

5. Fonnum F. (1984) Glutamate: A neurotransmitter in mammalian brain. $J$. Neurochem. 42: 1-11.

6. Hamberger A. (1971) Amino acid uptake in neuronal and glial cell fractions from rabbit cerebral cortex. Brain Res. 31: 169-178.

7. Choi DW. (1992) Amyotrophic lateral sclerosis and glutamate-Too much of a good thing? New Engl. J. Med. 326: 1493-1495.

8. Rothman SM. (1992) Excitotoxins: Possible mechanisms of action. Ann. N.Y. Acad. Sci. 648: 132-139.

9. Coyle JT, Puttfarcken P. (1993) Oxidative stress, glutamate, and neurodegenerative disorders. Science 262: 689-695.

10. Sorg O, Magistretti PJ. (1991) Characterization of the glycogenolysis elicited by vasoactive intestinal peptide, noradrenaline and adenosine in primary cultures of mouse cerebral cortical astrocytes. Brain Res. 563: 227-233.

11. Stoyanov T, Martin JL, Magistretti PJ. (1988) VIP binding sites in primary cultures of astrocytes. Eur. J. Neurosci. S1: 111-110.

12. Bradford MM. (1976) A rapid and sensitive method for the quantitation of microgram 
quantities of protein using the principle of protein-dye binding. Ann. Biochem. 72: 248254.

13. Grynkiewicz G, Poenie M, Tsien RY. (1985) A new generation of $\mathrm{Ca}^{2+}$ indicators with greatly improved fluorescence properties. J. Biol. Chem. 260: 3440-3450.

14. Williams DA, Fogarty KE, Tsien RY, Fay FS. (1985) Calcium gradients in single smooth muscle cells revealed by the digital imaging microscope using fura-2. Nature 318: 558561.

15. Qiu Z, Parsons KL, Gruol DL. (1995) Interleukin-6 selectively enhances the intracellular calcium response to NMDA in developing CNS neurons. J. Neurosci. 15: 6688-6699.

16. Gruol DL, Curry JG. (1995) Calcium signals elicited by quisqualate in cultured Purkinje neurons show developmental changes in sensitivity to acute alcohol. Brain Res. 673: $1-12$.

17. Greenwald RA, Moy WW. (1979) Inhibition of collagen gelation by action of the superoxide radical. Arthritis Rheum. 22: 251-259.

18. Royall JA, Ischiropoulos H. (1993) Evaluation of $2^{\prime}, 7^{\prime}$-dichlorofluorescin and dihydrorhodamine 123 as fluorescent probes for intracellular $\mathrm{H}_{2} \mathrm{O}_{2}$ in cultured endothelial cells. Arch. Biochem. Biophys. 302: 348-355.

19. DeMaster EG, Quast BJ, Redfern B, Nagasawa HT. (1995) Reaction of nitric oxide with the free sulfhydryl group of human serum albumin yields a sulfenic acid and nitrous oxide. Biochemistry 34: 11494-1 1499.

20. Koppenol WH, Moreno JJ, Pryor WA, Ischiropoulos H, Beckman JS. (1992) Peroxynitrite, a cloaked oxidant formed by nitric oxide and superoxide. Chem. Res. Toxicol. 5: 834-842.

21. Ueno S, Sugiyama M, Susa N, Furukawa Y. (1995) Effect of dimethylthiourea on chromium (VI)-induced DNA single-strand breaks in Chinese hamster V-79 cells. $\mathrm{Mu}$ tat. Res. 346: 247-253.

22. Halliwell B, Gutteridge JMC. (1989) Protection against oxidants in biological systems: The superoxide theory of oxygen toxicity. In: Halliwell B, Gutteridge, JMC (eds). Free Radicals in Biology and Medicine. Oxford University Press, Oxford, pp. 86-187.

23. Vanella A, Campisi A, Castorina C, et al. (1991) Antioxidant enzymatic systems and oxidative stress in erythrocytes with G6PD deficiency: Effect of deferoxamine. Pharmacol. Res. 24: 25-31.
24. Tappel AL. (1978) Glutathione peroxidase and hydroperoxides. Methods Enzymol. 52: 506-513.

25. Devesa A, O'Connor JE, Garciá C, Puertes IR, Viña JR. (1993) Glutathione metabolism in primary astrocyte cultures: Flow cytometric evidence of heterogeneous distribution of GSH content. Brain Res. 618: 181-189.

26. Yudkoff M, Pleasure D, Cregar L, Lin ZP, Nissim I, Stern J. (1990) Glutathione turnover in cultured astrocytes: Studies with $\left[{ }^{15} \mathrm{~N}\right]$ glutamate. J. Neurochem. 55: 137-145.

27. Kiechle FL, Malinski T. (1993) Nitric oxide. Biochemistry, pathophysiology, and detection. Am. J. Clin. Pathol. 100: 567-575.

28. Lewis RS, Deen WM. (1994) Kinetics of the reaction of nitric oxide with oxygen in aqueous solutions. Chem. Res. Toxicol. 7: 568-574.

29. McCord JM, Fridovich I. (1969) Superoxide dismutase. An enzyme function for erythrocuprein (hemocuprein). J. Biol. Chem. 244: 6049-6055.

30. Gutteridge JMC. (1993) Invited review: Free radicals in disease processes: A compilation of cause and consequence. Free Radic. Res. Commun. 19: 141-158.

31. Halliwell B, Gutteridge JMC. (1984) Oxygen toxicity, oxygen radicals, transition metals and disease. Biochem. J. 219: 1-14.

32. Cheeseman KH, Slater TF. (1993) Free radicals in medicine. Br. Med. Bull. 49: 479-724.

33. Szent-Gyorgyi A. (1978) The living state and cancer. Ciba Found. Symp. 67: 3-18.

34. Moyer VD, Cistulli CA, Vaslet CA, Kane AB. (1994) Oxygen radicals and asbestos carcinogenesis. Environ. Health Perspect. 102(Suppl. 10): 131-136.

35. Wei H. (1992) Activation of oncogenes and/or inactivation of anti-oncogenes by reactive oxygen species. Med. Hypotheses 39: 267-270.

36. Downey JM. (1990) Free radicals and their involvement during long-term myocardial ischemia and reperfusion. Annu. Rev. Physiol. 52: 487-504.

37. Ransohoff J. (1978) Free radicals in cerebral ischemia. Stroke 9: 445-447.

38. Johnson KJ, Weinberg JM. (1993) Postischemic renal injury due to oxygen radicals. Curr. Opin. Nephrol. Hypertension 2: 625-635.

39. Chiueh CC, Gilbert DL, Colton CA. (1994) The Neurobiology of $\mathrm{NO}$ and $\mathrm{OH}$. The New York Academy of Sciences, New York, Vol. 738.

40. Gutteridge JMC. (1994) Hydroxyl radicals, iron, oxidative stress, and neurodegeneration. Ann. N.Y. Acad. Sci. 738: 201-213. 
41. Halliwell B. (1992) Reactive oxygen species and the central nervous system. J. Neurochem. 59: 1609-1623.

42. Shinar E, Navok T, Chevion M. (1983) The analogous mechanisms of enzymatic inactivation induced by ascorbate and superoxide in the presence of copper. J. Biol. Chem. 258: $14778-14783$.

43. Holmberg P. (1984) The physics and chemistry of free radicals. Med. Biol. 62: 68-70.

44. Grisham MB. (1995) Interaction between nitric oxide and superoxide: Role in modulating leukocyte adhesion in the postischemic microvasculature. Transplant. Proc. 27: 2842-2843.

45. Huie RE, Padmaja S. (1993) The reaction of NO with superoxide. Free Radic. Res. Commun. 18: 195-199.

46. Squadrito GL, Pryor WA. (1995) The formation of peroxynitrite in vivo from nitric oxide and superoxide. Chemico-Biol. Int. 96: 203-206.

47. Trotti D, Rossi D, Gjesdal O, et al. (1996) Peroxynitrite inhibits glutamate transporter subtypes. J. Biol. Chem. 271: 5976-5979.

48. Preclik G, Stange EF, Ditschuneit H. (1992) Limited utilization of exogenous arachidonic acid by the prostaglandin cyclooxygenase in gastric mucosa: The role of protein binding, glutathione peroxidase, and hydrogen peroxides. Prostaglandins 44: 177-197.

49. Chaudière J, Wilhelmsen EC, Tappel AL. (1984) Mechanism of selenium-glutathione peroxidase and its inhibition by mercaptocarboxylic acids and other mercaptans. J. Biol. Chem. 259: 1043-1050.

50. Scott MD, Wagner TC, Chiu DT. (1993) Decreased catalase activity is the underlying mechanism of oxidant susceptibility in glucose-6-phosphate dehydrogenase-defi-

Communicated by F. Bloom. Accepted May 7, 1997. cient erythrocytes. Biochim. Biophys. Acta 1181: 163-168.

51. Volterra A, Trotti D, Cassutti P, et al. (1992) High sensitivity of glutamate uptake to extracellular free arachidonic acid levels in rat cortical synaptosomes and astrocytes. J. NeUrochem. 59: 600-606.

52. Yu ACH, Chan PH, Fishman RA. (1986) Effects of arachidonic acid on glutamate and $\gamma$-aminobutyric acid uptake in primary cultures of rat cerebral cortical astrocytes and neurons. J. Neurochem. 47: 1181-1189.

53. Stella N, Tencé M, Glowinski J, Prémont J. (1994) Glutamate induces the release of arachidonic acid by interacting with an atypical metabotropic receptor present on mouse brain astrocytes. Renal Physiol. Biochem. 17: 153-156.

54. Rees R, Smith D, Li TD, et al. (1994) The role of xanthine oxidase and xanthine dehydrogenase in skin ischemia. J. Surg. Res. 56: 162-167.

55. McCord JM. (1985) Oxygen-derived free radicals in postischemic tissue injury. New Engl. J. Med. 312: 159-163.

56. Ogata T, Nakamura $Y$, Tsuji $K$, Okumura $H$, Kataoka K, Shibata T. (1996) Role of aspartate in ischemic spinal cord damage. J. Orthopaed. Res. 14: 504-510.

57. Duffy S, McVicar BA. (1996) In vitro ischemia promotes calcium influx and intracellular calcium release in hippocampal astrocytes. J. Neurosci. 16: 71-81.

58. Mitani A, Yanase $H$, Namba $S$, Shudo $M$, Kataoka K. (1995) In vitro ischemia-induced intracellular $\mathrm{Ca}^{2+}$ elevation in cerebellar slices: A comparative study with the values found in hippocampal slices. Acta Neuropathol. 89: 2-7. 